\section{Hormone}

Research

Claude J. Migeon a

Amy B. Wisniewski

a Department of Pediatrics,

Division of Pediatric Endocrinology,

Johns Hopkins Medical Institution, and

b Department of Psychology, Behavioral Endocrinology Group, Johns Hopkins University, Baltimore, Md., USA
Horm Res 1998;50:245-251

\title{
Sexual Differentiation: From Genes to Gender
}

\section{Key Words}

Gender

Sex differentiation

Genitalia

Internal ducts

Gonads

\begin{abstract}
A person's sex can be considered across various levels. To illustrate, genes, hormones, and genitalia can all be considered physical markers of a person's sex. In addition to physical markers, behaviors such as gender role, gender identity and sexual orientation can be perceived as stereotypically male or female. The purpose of this review is to summarize current knowledge of sexual differentiation which emphasizes genetic and hormonal mechanisms that result in male and female development of gonads and genitalia. Finally, consideration is given to associations between genetic sex, gonadal sex, and hormonal sex with gender.
\end{abstract}

\section{Introduction}

Stedman's Medical Dictionary defines sex as the biological qualities that distinguish between male and female. These qualities are expressed by an individual's chromosomal, gonadal, morphological (internal and external) and hormonal characteristics. Sex is also defined as the physiological and psychological processes within an individual which prompt behavior related to procreation and/or erotic pleasure. Gender is defined as the sex of assignment. Gender can be further partitioned into gender role and gender identity, which refer to the sex of a person assigned by society and the sex of a person assigned by himself respectively [1]. An attempt is made to describe associations between biological qualities of sex and gender in humans, and also to bring attention to the need for further investigation (fig. 1).
Fig. 1. Associations between biological characteristics of sex.

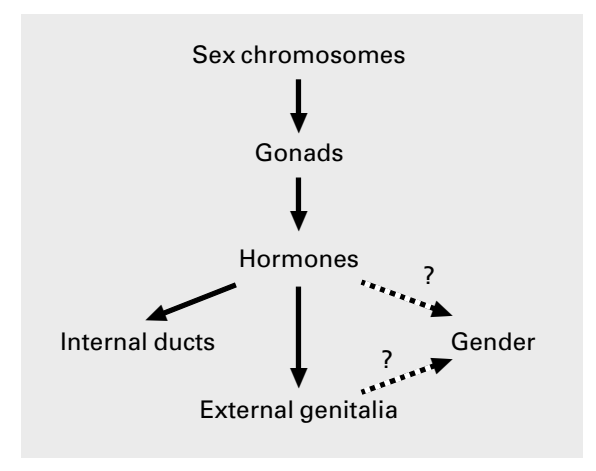

\section{Genetic Sex}

The genetic sex of an individual is considered to be the first step in sex differentiation. Genetic sex is determined at fertilization, when fusion of an egg and a sperm occurs. An egg has a chromosome complement of $23, \mathrm{X}$ and a

Claude J. Migeon, MD, Professor of Pediatrics

Johns Hopkins School of Medicine, CMSC 3-110

600 N. Wolfe Street

Baltimore, MD 21287-3311 (USA)

Tel. +1 410955 6463, Fax +1 4109559773 
sperm has a complement of either $23, \mathrm{X}$ or $23, \mathrm{Y}$ [2]. The diploid cell which results from this fusion has either a 46,XX (genetic female) or a 46,XY (genetic male) karyotype [3]. Once fusion of parental gametes occurs genetic sex is established for an individual.

\section{Undifferentiated Structures}

During the first 6 weeks of embryonic development the gonadal ridge, germ cells, internal ducts, and external genitalia are bipotential in both 46,XX and 46,XY embryos. Under circumstances of sex differentiation: (1) the bipotential gonadal ridges differentiate into either ovaries or testes; (2) germ cells develop into either oocytes or spermatocytes; (3) one of the two sets of internal ducts develop while the other regresses, and (4) bipotential external genitalia either masculinize or remain feminine. In instances of normal sex differentiation, the undifferentiated structures are complementary to each other regarding classification as male or female. In contrast, individuals with conditions of intersex show varying degrees of discordance between the sex of their gonads, internal ducts and external genitalia.

\section{Gonadal Ridges}

A bipotential gonadal ridge is located medially on the urogenital ridge which can be detected by 5 weeks of gestation [4-6]. The gonadal ridge is considered to be a bipotential gonad once germ cells migrate to this structure. Germ cells are formed in the yolk sac and migrate at approximately 5 weeks of embryonic development. They contain a $46, \mathrm{XX}$ or $46, \mathrm{XY}$ complement [5] and undergo mitotic divisions during the process of differentiation, with these divisions occurring in both the fetal testis and ovary $[4,7]$.

\section{Undifferentiated Sex Ducts: The Wolffian Duct \\ System and the Müllerian Duct System}

The 46,XX and 46,XY embryos each possess a set of wolffian ducts as well as a set of müllerian ducts early in development. The wolffian ducts are detected during the 4 th gestational week $[6,8]$ and the müllerian ducts appear later, during the 6th gestational week [4].

The wolffian duct system results in the formation of the epididymis, vas deferens, and seminal vesicles if certain physiological conditions are met. In contrast, the müllerian duct system will develop under a different set of physiological conditions into the fallopian tubes, uterus, and posterior portion of the vagina.

\section{External Genitalia}

The cloacal folds, situated around the cloacal membrane, are detectable at 5 weeks of embryonic development. Tissue destined to form the external genitalia is located at the cranial region of the cloacal folds and separates from the posterior region which will become the anus. This tissue is bipotential, and thus identical in $46, \mathrm{XX}$ and 46,XY embryos until 9 weeks of embryonic development [6].

\section{Gonadal Sex}

\section{Testis Determination}

The bipotential gonad and associated germ cells develop into a testis containing type-A spermatogonia around 6 weeks of embryonic development if specific influences from SRY, SF-1, and SOX-9 are evident (these genetic components of testis determination are discussed in the following section). The first of three steps observed in testis determination is the appearance of Sertoli cells which organize themselves into seminiferous tubules and surround the germ cells. Sertoli cells produce müllerianinhibiting substance (MIS) [9] which is necessary to inhibit development of the müllerian duct system (fig. 2).

The next step in testis determination from a bipotential gonad is the appearance of Leydig cells [5, 10]. Once Leydig cells are present and stimulated by chorionic gonadotropins early or by fetal pituitary gonadotropins later, the fetal testis is capable of producing testosterone [11].

The third step in testis determination is differentiation and development of male germ cells. In the testis, germ cells undergo mitotic arrest and subsequent formation of spermatogonia. Two distinct mechanisms exist to explain mitotic arrest of male germ cells: (1) physical contact between germ cells and Sertoli cells [12], and (2) mitoticinhibiting substance from the seminiferous tubules [13, 14].

\section{Genetic Control of Testis Determination}

The Wilms' tumor gene, WT1, is an important transcription factor for the development of a bipotential gonad upon which testicular or ovarian differentiation occurs [15]. So-called knock-out studies with a nuclear receptor, steroidogenic factor-1 (SF-1) have shown that this factor is necessary for the formation of the bipotential gonad. Indeed, the simultaneous increase in SF-1 transcription and of the DAX-1 transcript gene at the Xp21p22 locus suggest that both SF-1 and DAX-1 are needed 
Fig. 2. Steps necessary for testis develop-

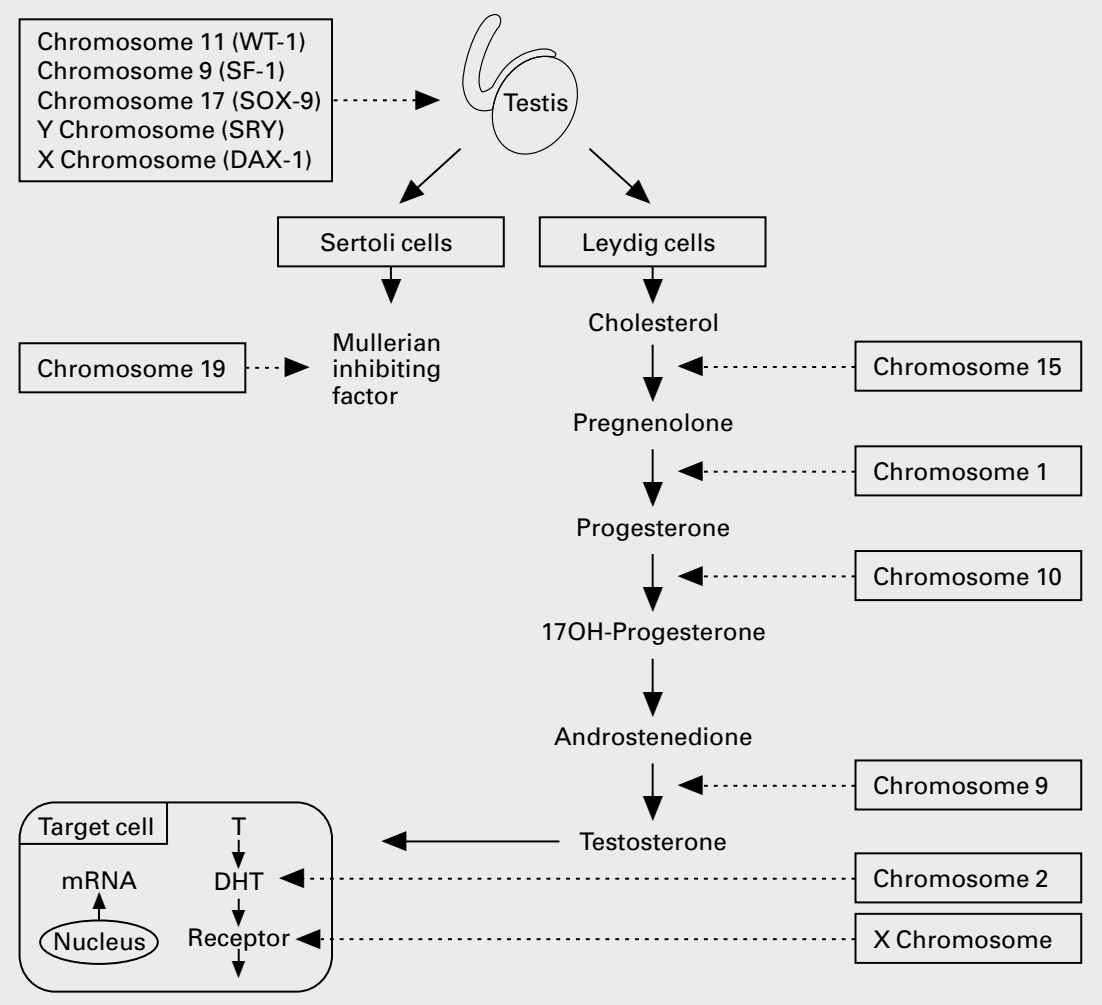
ment.

for the early growth of the gonads. Following development of a bipotential gonad, several genes are required for the complete process of testis determination. The sexdetermining region of the Y chromosome (SRY) is the locus for the testis-determining factor (TDF), and it is located in a 35-kb segment on the short arm of the Y chromosome [16]. If a developing embryo possesses a functional SRY gene, the bipotential gonad subsequently develops into a testis. The absence of SRY results in gonadal streaks in individuals with 46,XY complete gonadal dysgenesis [17]. SF-1 appears to be involved not only in the processes of testis determination but also in müllerian duct regression [18] as it binds to a regulatory element associated with MIS genes [19]. SF-1 and DAX-1 expression are detectable prior to SRY expression. It is possible that the role of SRY is to potentiate the transcription of SF-1, which in turn stimulates the expression of maledifferentiating genes while it suppresses the expression of DAX-1, a stimulant of female-differentiating genes. In addition to SRY and SF-1, SOX-9 also appears important for testis determination and may function by interacting with SRY [20]. Later in testicular development, SF-1 reg- ulates cytochrome P450 steroidogenic enzymes of the Leydig cells.

\section{Testicular Determination in the Absence of TDF: The} Importance of Autosomal or X Chromosome Genes

Testicular determination is observed in both $46, \mathrm{XX}$ males and 46,XX true hermaphrodites. While SRY can on occasion be translocated from the $\mathrm{Y}$ to an X chromosome in these individuals, the majority of $46, \mathrm{XX}$ males and hermaphrodites studied thus far do not possess a translocated SRY gene [21, 22]. These findings confirm that autosomal or $\mathrm{X}$ chromosome genes also play an important role in testis determination.

In addition, male-to-female sex reversal has been observed in 46,XY people in relation to duplication of a gene at Xp21-p22 [23]. The presence of two active copies of Xp21 is termed, dosage-sensitive sex reversal (DSS), and DSS is located on a $160-\mathrm{kb}$ region of X21 [24]. Recently, the DSS gene was confirmed to be DAX-1 [25]. As mentioned above DAX-1 appears to promote the early formation of bipotential gonads. Since a double dose of DAX-1 can override testis development in the presence of 
$A=20$-Hydroxylase/22-hydroxylase/20,22-desmolase

$\mathrm{B}=3 \beta$-Hydroxysteroid dehydrogenase-isomerase

$C=17-$ Hydroxylase

$\mathrm{D}=17,20$-Desmolase

$\mathrm{E}=$ Aromatase

$\mathrm{F}=17-$ Ketosteroid reductase

$\mathrm{G}=5 \delta$-Reductase

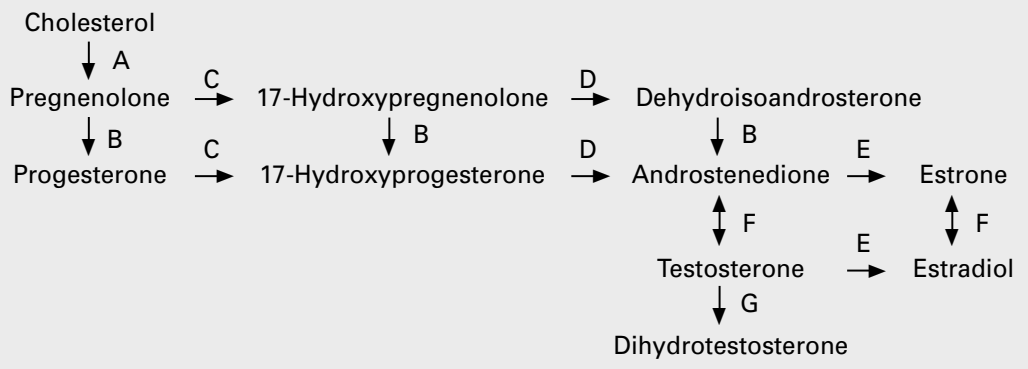

Fig. 3. Biochemical pathways necessary for steroid hormone production.

\section{Hormonal Sex}

\section{Müllerian Inhibiting Substance}

MIS is important for regression of the müllerian duct system in males and for influencing testicular formation. MIS is also detected in females, but only after the müllerian ducts are committed to development. The presence of MIS in females and in testes suggests additional functions of MIS in fetal development [20,29, 30].

\section{Testosterone}

Testosterone synthesis by fetal Leydig cells starts at 8 weeks of gestation and is maximally produced around week 13 of gestation [31]. Testosterone is crucial for development of both the wolffian duct system and the masculinization of the external genitalia. The biochemical precursor of totestosterone is cholesterol. The four required enzymes constituting the biochemical pathway from cholesterol to testosterone are cholesterol side-chain cleavage, 33-hydroxysteroid dehydrogenase, $17 \alpha$-hydroxylase and 17-ketosteroid reductase. Cells of the external genitalia contain a $5 \alpha$-steroid reductase which potentiates masculinization by transforming testosterone to dihydrotestosterone, the most biologically active androgen (fig. 3).

\section{Estrogens}

The conversion of $\mathrm{C}^{19}$ androgens to $\mathrm{C}^{18}$ estrogens is a result of the action of a specific cytochrome P450, aromatase. Aromatase is detectable in fetal tissue [32] indicating that aromatization of androgens to estrogens is biochemically feasible during fetal development. 


\section{Control of Steroid Secretion}

Sex steroid hormones must bind to appropriate nuclear receptors to be physiologically active. The resulting hormone-receptor complex recognizes a specific response element of the promoter of steroid-responsive genes and interacts with RNA polymerase II to form a large transcriptional activation complex. Expression of specific messenger RNAs results from this transcriptional activation complex, which then leads to translation and protein synthesis. If any one of the steps involved in androgen transcription/ translation is defective, the result is a lack of masculinization of internal sex ducts and external genitalia [33].

\section{Phenotypic Sex}

Phenotypic sex includes internal sex ducts and external genitalia. Of the internal duct systems, wolffian duct development depends upon the presence of testosterone, and müllerian duct development depends upon the absence of MIS. The fetal testis produces testosterone in the Leydig cells and MIS in the Sertoli cells. The fetal ovary does not produce either testosterone or MIS at the time of internal duct differentiation [29]. As a result, a fetus with testes will have concomitant development of the wolffian system and regression of the müllerian system. A fetus with ovaries will exhibit development of the müllerian duct system and regression of the wolffian duct system.

\section{External Genitalia in Males}

Timing is critical for masculinization of external genitalia. Masculinization typically begins at 7 weeks of gestation. If androgens are not present to masculinize external genitalia until week 12 or later, full masculinization cannot take place.

While testosterone is the sex steroid hormone which promotes the growth of wolffian ducts, dihydrotestosterone is necessary to masculinize external genitalia [11]. Masculinization of external genitalia includes increasing anogenital distance, fusion of urethral folds, and growth and medial fusion of scrotal swellings. The penis forms from the genital tubercle, and continues to grow throughout gestation.

\section{External Genitalia in Females}

In the absence of testosterone, the labia majora and labia minora form from the genital swelling and urethral folds, respectively. The clitoris forms from the genital tubercle. The opening of the urethra and vagina are observed below the clitoris.

\section{Other Phenotypic Sex Differences}

Although the appearance of the external genitalia is the basis for the diagnosis of sex at birth, there are many other differences related to sex. There are more male than female newborns and males are heavier than females. On the other hand, male infantile mortality is generally greater than female infantile mortality. Puberty occurs earlier in girls than in boys. Bone structure, particularly in the pelvis, is quite different in the two sexes. Men are taller and heavier than women, and longevity is greater in females than in males. It is likely that some of these differences are related to the type of sex hormones secreted, whereas other differences are not clearly understood.

As gender is the summation of various somatic differences which have been recognized, integrated and interpreted in the central nervous system, it is not surprising that investigators have searched for anatomical variations of brain structure according to sex and gender. Indeed, morphological sex differences have been observed in the human hypothalamus, complemented by gender differences in the suprachiasmatic nucleus [34].

\section{Gender}

Behaviors differ between males and females. The terms gender identity, gender role, and sexual orientation provide the focus for the present consideration of gender [35].

Gender identity refers to the sex a person identifies with personally (i.e., I think of myself as male or female). Gender role refers to the sex society assigns to a person (i.e., others regard me as male or female) [36]. Sexual orientation refers to erotic attraction toward members of the same sex (homosexual), the opposite sex (heterosexual), or both (bisexual).

Gender identity and gender role do not correspond with sex of rearing for some people. For example, a man with discordant gender identity views himself as a female while a man who takes on the public persona of a woman is discordant for gender role. Conditions of intersexuality provide a unique opportunity to examine gender in individuals who experience anomalous sex differentiation.

\section{Congenital Adrenal Hyperplasia due to}

21-Hydroxylase Deficiency

Congenital adrenal hyperplasia (CAH) due to 21hydroxylase deficiency is an autosomal recessive disorder. Clinical manifestations of CAH include decreases in cortisol secretion and subsequent increases in ACTH 
secretion. As a result of increased ACTH output, the production of adrenal androgens increase, leading to masculinization of external genitalia in female fetuses.

$\mathrm{CAH}$ girls and women provide an opportunity to investigate gender in individuals who are concordant for genetic sex $(46, \mathrm{XX})$ and internal duct sex (müllerian development and wolffian regression), but who are discordant for hormonal sex (prenatal exposure to excessive androgens) and external genital sex (ambiguous or fully masculinized).

A number of studies report masculinized or defeminized play behavior (an index of gender role) in $\mathrm{CAH}$ girls. In contrast, $\mathrm{CAH}$ females do not typically report a conflict with their female gender identity [37-39]. Concerning sexual orientation, some studies indicate increased bisexual/homosexual fantasy and behavior in CAH women while others do not.

A great deal of variability exists in the expression of masculinized/defeminized behaviors among CAH patients studied thus far. One explanation for this variability is that varying degrees of androgen exposure and genital masculinization in these girls differentially influences their behavior. Another possibility, at least in terms of sexual behavior, is the practical issue of the adequacy of vaginal constructive surgery for heterosexual intercourse. In CAH studies comparing the salt-wasting (SW) form of $\mathrm{CAH}$ with the simple-virilizing (SV) form, SW women were less likely to be married or had fewer children than SV women [37]. The SW/SV distinction is important because SW women were less likely to report a satisfactory introitus, and correspondingly were less likely to report heterosexual activity. At present, the clearest predictor of heterosexual behavior in $\mathrm{CAH}$ populations is an introitus considered adequate for heterosexual sex.

\section{Androgen-Insensitivity Syndrome}

Normal male sexual differentiation requires that every one of the differentiating steps occurs in the appropriate fashion with appropriate timing. Deviation at any step can result in female or ambiguous external genitalia. One possible deviation involves the partial or complete absence of androgen receptor activity. A complete absence results in complete androgen insensitivity. These subjects present female-appearing external genitalia, lack of sexual hair and breast development while simultaneously producing male-typical concentrations of testosterone. Yet, these persons report a feminine gender role and gender identity $[39,40]$. Perhaps the fact that their original female sex of rearing influenced their gender development.
When the mutation of the androgen receptor gene results in partial receptor activity, the subjects present various degrees of ambiguity of the external genitalia. At puberty there is poor sexual hair growth and breast development. Sex of rearing may be male or female but little is known about gender in this population.

\section{Ablatio Penis}

Recently, investigations of gender were reported for 2 individuals who experienced normal male sex differentiation prenatally, but who suffered from ablatio penis postnatally. In each case, both individuals were assigned and raised as girls. In one instance, the individual during adolescence chose to have a sex re-reassignment to that of a male. Additionally, this individual identifies himself as a heterosexual male who displayed masculine play behavior during his childhood while living as a girl [41]. In contrast, a second case was reported in which the individual identifies with being a bisexual female [42].

\section{Conclusions}

Sex is multifaceted. Associations clearly exist among many of the steps comprising sex differentiation of genitalia and reproductive tracts. What is not well understood at this point is the influence of these steps on behavior in humans. More investigations of gender are needed among intersex populations, as well as among the general population, to determine whether the physiological processes of sex differentiation affect gender role, gender identity and sexual orientation. 


\section{References}

1 Stedman's Medical Dictionary, ed 24. Baltimore, Williams \& Wilkins, 1982.

2 Ford CE, Hamerton JL: The chromosomes of man. Nature 1956;178:1020.

3 Tijo JH, Levan A: The chromosomal number of man. Hereditas 1956;42:1.

4 Langman L: Medical Embryology, ed 2. Baltimore, Williams \& Wilkins, 1969.

5 Jirasek JE: Development of the genital system and male pseudohermaphroditism; in Cohen MM (ed): Baltimore, Johns Hopkins Press, 1971.

6 Jirasek JE: Morphogenesis of the genital system in the human; in Blandau RJ, Bergsma D (eds): Birth Defects: Original Article Series. New York, Liss, 1977, vol 13, p 13.

7 Witschi E: Migration of germ cells of human embryos from the yolk sac to the primitive gonadal folds. Contrib Embryol 1948;32:67.

8 Josso N: Physiology of sex differentiation. A guide to the understanding and management of the intersex child; in Josso N (ed): The Intersex Child. Basel, Karger, 1981, pp 1-13.

9 Magre S, Jost A: Dissociation between testicular organogenesis and endocrine cytodifferentiation of Sertoli cells. Proc Natl Acad Sci USA 1984;81:7831.

10 Pelliniemi LJ, Niemi M: Fine structure of the human foetal testis. I. The interstitial tissue. Z Zellforsch 1969;99:507.

11 Siiteri PK, Wilson JD: Testosterone formation and metabolism during male sexual differentiation in the human embryo. J Clin Endocrinol Metab 1974;38:113.

12 McLaren A: Somatic and germ-cell sex in mammals. Philos Trans R Soc Lond B Biol Sci 1988;322:3-9.

13 Byskov AG: Differentiation of mammalian embryonic gonad. Physiol Rev 1986;66:71117.

14 Jost A, Magre S: Control mechanisms of testicular differentiation. Philos Trans R Soc Lond B Biol Sci 1988;322:55-61.

15 MacLean HE, Warne GL, Zajac JD: Intersex disorders: Shedding light on male sexual differentiation beyond SRY. Clin Endocrinol 1997; 46:101.

16 Sinclair AH, Berta P, Palmer MS, Hawkins JR, Griffiths BLM, Smith J, Foster JW, Frischauf A, Lovell-Badge R, Goodfellow PN: A gene from the human sex-determining region encodes a protein with homology to a conserved DNA-binding motif. Nature 1990;346:240.
17 Fechner PY: The role of SRY in mammalian sex determination. Acta Paediatr Jpn 1996;38: 380 .

18 Smith MJ: Turning on sex. Curr Biol 1994;4: 10.

19 Shen W, Moore CCD, Ikeda Y, Parker KL, Ingraham HA: Nuclear receptor steroidogenic factor 1 regulates the mullerian inhibiting substance gebe: A link to the sex determination cascade. Cell 1994;77:651.

20 McElreavey K, Barbaux S, Ion A, Fellous M: The genetic basis of murine and human sex determination. Heredity 1995;75:599.

21 Berkovitz GD, Fechner PY, Marcantonio SM, Bland G, Stetten G, Goodfellow PN, Smith $\mathrm{KD}$, Migeon CJ: The role of the sex-determining region of the $\mathrm{Y}$ chromosome (SRY) in the etiology of 46,XX true hermaphroditism. Hum Genet 1992;88:411.

22 Fechner PY, Marcantonio SM, Jaswaney V, Stetten G, Goodfellow PN, Migeon CJ, Smith KD, Berkovitz GD: The role of the sex determining region $\mathrm{Y}$ gene in the etiology of $46, \mathrm{XX}$ maleness. J Clin Endocrinol Metab 1993;76: 690.

23 Ogata T, Matsuo N: Testis determining gene(s) on the X chromosome short arm: Chromosomal localization and possible role in testis determination. J Med Genet 1994;31:349.

24 Bardoni B, Zanaria E, Guiolo S, Floridia G, Worley K, Tonini G, Ferrante E, Chiumello G, McCabe ERB, Fraccaro M, Zuffardi O, Camerino G: A dosage sensitive locus at chromosome Xp21 is involved in male to female sex reversal. Nat Genet 1994;7:497.

25 Swain A, Narvaez V, Burgoyne P, Camerino G, Lovell-Badge R: Dax1 antagonizes Sry action in mammalian sex determination. Nature 1998;391:761.

26 George FW, Wilson JD: Conversion of androgen to estrogen by human fetal ovary. J Clin Endocrinol Metab 1978;47:550.

27 Luo X, Ikeda Y, Parker KL: A cell-specific nuclear receptor is essential for adrenal and gonadal development and sexual differentiation. Cell 1994;77:481

28 Burris TP, Guo W, Le T, McCabe ERB: Identification of a putative steroidogenic factor-1 response element in the DAX-1 promoter. Biochem Biophys Res Commun 1995;214:576.

29 Josso N: Hormonal regulation of sexual differentiation. Semin Perinatol 1992;16:274.

30 Huhtaniemi I: Fetal testis - A very special endocrine organ. Eur J Endocrinol 1994;130: 25 .
31 Tapanainen J, Kellokumpu-Lehtinen P, Pelliniemi L, Huhtaniemi I: Age-related changes in endogenous steroids of human fetal testis during early and midpregnancy. J Clin Endocrinol Metab 1981;52:98.

32 Price T, Aitken J, Simpson ER: Relative expression of aromatase cytochrome P450 in human fetal tissue as determined by competitive polymerase chain reaction amplification. J Clin Endocrinol Metab 1992;74:879.

33 Brown TR, Migeon CJ: Cultured human skin fibroblasts for the study of androgen action. Mol Cell Biochem 1981;36:3.

34 Swaab DF, Gooren LJG, Hofman MA: Gender and sexual orientation in relation to hypothalamic structures. Horm Res 1992;38:51.

35 Zucker KJ, Bradley SJ: Gender Identity Disorder and Psychosexual Problems in Children and Adolescents. New York, Guilford Press, 1995.

36 Money J: Biographies of Gender and Hermaphroditism in Paired Comparisons. New York, Elsevier, 1991.

37 Mulaikal RM, Migeon CJ, Rock JA: Fertility rates in female patients with congenital adrenal hyperplasia dueto 21-hydroxylase deficiency. N Engl Med 1987;316:178.

38 Dittmann RW, Kappes MH, Kappes ME, Borger D, Meyer-Bahlburg HFL, Stegner H, Willig RH, Wallis H: Congenital adrenal hyperplasia. II. Gender-related behavior and attitudes in female salt-wasting and simple-virilizing patients. Psychoneuroendocrinology 1990; 15:421-434

39 Money J, Schwartz M, Lewis VC: Adult erotosexual status and fetal hormonal masculinization: 46,XX congenital virilizing adrenal hyperplasia and 46,XY androgen insensitivity syndrome compared. Psychoneuroendocrinology 1984;9:405.

40 Migeon CJ, Brown TR, Fichman KR: Androgen insensitivity syndrome; in Josso $\mathrm{N}$ (ed): Pediatric and Adolescent Endocrinology: The Intersex Child. Basel, Karger, 1981, vol 8, p 171.

41 Diamond M, Sigmundson K: Sex reassignment at birth: Long-term review and clinical implications. Arch Pediatr Adolesc Med 1997;151: 298-304.

42 Bradley SJ, Oliver GD, Chernick AB, Zucker $\mathrm{KJ}$ : Experiment of nature: Ablatio penis at 2 months, sex reassignment at 7 months, and a psychosexual follow-up in young adulthood. Pediatrics 1998;102:e9. 
Copyright: S. Karger AG, Basel 1998. Reproduced with the permission of S. Karger AG, Basel. Further reproduction or distribution (electronic or otherwise) is prohibited without permission from the copyright holder. 